\title{
Sediment Transport and Disturbance on an Intertidal Sandflat: Infaunal Distribution and Recolonization
}

\author{
Jonathan Grant* \\ Belle W. Baruch Institute for Marine Biology and Coastal Research and Department of Biology, University of South Carolina, \\ Columbia, South Carolina 29208, USA
}

\begin{abstract}
Aspects of sediment movement in relation to the distribution and transport of infaunal crustaceans were studied on a high-energy sandflat in North Inlet, South Carolina, USA. Lower intertidal areas $(+0.2 \mathrm{~m}$ ) were characterized by ebb-dominated ripples of $15-20 \mathrm{~cm}$ wavelength and $4-5 \mathrm{~cm}$ amplitude. Although ebb current velocity and ripple size decreased in higher intertidal areas $(+0.6 \mathrm{~m})$, tracer experiments indicated that the depth of tidal disturbance in the sediment $(0-3 \mathrm{~cm})$ was not significantly different between low and high intertidal zones. Calculation of critical Froude numbers from laboratory flume experiments revealed that ripple migration occurred for some portion of ebb flow at all intertidal levels. The number of burrowing crustaceans was significantly greater in ripple crests than troughs along a transect in the lower intertidal, but not within a small sampling area at the same tidal level. Faunal distribution in bedforms was apparently related to active preference rather than passive hydrodynamic sorting. Azoic sand placed in the intertidal zone was colonized rapidly by adult crustaceans (mostly haustorid amphipods) settling from the water column. Acanthohaustorius millsi, a shallow sediment dweller, appeared after a single tidal day. In contrast, Pseudohaustorius caroliniensis, a deeper-living haustoriid usually not subjected to tidal disturbance, did not colonize until after 23 tidal days. These experiments indicated that azoic sediment would have attained the crustacean density of surrounding sand in approximately one month. It is suggested that the suspension of macrofauna above high-energy bottoms and subsequent removal by predators may be an important link in benthic-pelagic coupling.
\end{abstract}

\section{INTRODUCTION}

Tidally-mediated exchange of materials between benthic environments and the overlying water column is an important process in shallow marine habitats. Much of this interaction has been studied as fluxes of nutrients, detritus, fecal pellets, and microflora from the benthos (see review by Tenore, 1977). Most information on the relationship of tidal currents to benthicpelagic coupling has been obtained from mud or muddy-sand substrata in large embayments where the suspended load is high. Despite the fact that estuaries and bays contain extensive areas of greater tidal velocity and sediment movement, ecological studies of the latter high-energy habitats are limited to descriptive

\footnotetext{
- Present address: Department of Oceanography, Dalhousie University, Halifax, Nova Scotia, Canada B3H 4J1

faunal surveys (e.g. Maurer and Aprill, 1979). Detrital exchange from clean sand to the water column may be minor compared to muddier areas, but the increased motion of the bed on sand bottoms may cause tidal transport of macrofauna to be more significant than in finer substrata. A number of infaunal taxa, particularly peracarid crustaceans, are known to occur both passively and actively above mobile sand bottoms (e.g. Fincham, 1970), and recent flume experiments have shown that haustoriid amphipods may be washed out of the sediment by current disturbance (Grant, 1980).

The potential for passive suspension of these animals is related to both their distribution in the sediment column, and the degree of tidal disturbance to the bed. Furthermore, the sorting of settling material that occurs during bedform migration may result in a nonrandom distribution of animals in the substratum. Because recent benthic studies have emphasized the 
importance of disturbance and small-scale patterns in marine soft-bottom communities (Woodin, 1978; Eckman, 1979), the lack of similar information on bedform microtopography is conspicuous.

The present study combines field experiments on an estuarine sandflat with laboratory flume studies to quantify (1) tidal current velocity and sediment transport, (2) dispersion of burrowing crustaceans in the mobile layer of the sediment, and (3) aspects of their transport into the water column and rate of re-entry back into the sand.

\section{MATERIALS AND METHODS}

\section{Sediment Movement}

Sampling and field experiments took place on Debidue Flat, a large intertidal sandflat ( 2 ha) in the North Inlet Estuary near Georgetown, South Carolina, USA $\left(33^{\circ} 19^{\prime} \mathrm{N} ; 79^{\circ} 08^{\prime} \mathrm{W}\right)$. This site is within $0.5 \mathrm{~km}$ of the North Inlet and associated with the flood tidal delta system (Humphries, 1977). Depth of sediment disturbance due to semidiurnal tidal currents (neap range = $0.9 \mathrm{~m}$ ) was studied in March, 1978 at low (+ $0.2 \mathrm{~m}$ ), mid (0.4), and high (0.6) intertidal levels using sand from Debidue Flat stained with Sudan III (red) dissolved in benzene (Myers, 1977). In each experiment, a column of dyed sand $(4.5 \mathrm{~cm}$ diameter) within a transparent core was inserted into the sediment to a depth of $10 \mathrm{~cm}$ (Steele et al., 1970). Four replicate cores were equally spaced over a $5 \mathrm{~m}$ transect perpendicular to the direction of ebb tidal flow. Core tubes were removed when the dyed sand was flush with the surrounding sediment surface, leaving the tracer column intact. Following the second high tide $(-20 \mathrm{~h})$, current measurements were made above the cores with a Gurley-Teledyne current meter every 20 min at surface, middle, and near bottom $(\sim 5 \mathrm{~cm})$ depths until the site was exposed. Because the tidal channel that drains Debidue Flat is dominated by ebb-tidal currents (Kjerve and Proehl, 1979), velocity was measured only on falling tides. Dyed sand was re-cored at low tide and depth of disturbance over one tidal day calculated as the difference in height of the red sand from $10 \mathrm{~cm}$. As a control of this technique, tracer columns were emplaced and immediately re-cored. Coring alone did not affect the height of the tracer column.

A salt water flow-through laboratory flume (Rhoads et al., 1977) with a flow channel $45 \mathrm{~cm}$ long $\times 10 \mathrm{~cm}$ wide $\times 17.5 \mathrm{~cm}$ high was used to observe critical erosion velocity of the bed and the rate of ripple migration (see also Grant, 1980). Natural sediment from Debidue Flat was used in flume studies.

\section{Faunal Distribution}

Field samples from bedforms were taken at low tide from the lower intertidal zone $(+0.2 \mathrm{~m})$ in July 1978 within a small area $\left(\sim 2 \mathrm{~m}^{2}\right)$, and in August 1978 at even intervals along a transect parallel to the water line. In both months, bedform spacing and height were recorded and 5 or 6 PVC cores (5 $\mathrm{cm}$ diameter) were obtained at each of three parts of a ripple: crest surface $(0-5 \mathrm{~cm}$ depth), crest subsurface (5-10), and adjacent trough $(0-10)$. After samples were sieved in the laboratory through a $0.5 \mathrm{~mm}$ mesh, crustaceans (the dominant macrofauna of this site, see Holland and Polgar, 1976) were identified, measured, and preserved in $40 \%$ isopropanol.

\section{Recolonization Experiments}

Recolonization experiments were carried out in July and August 1978. Surface sediment was collected from the sample site, frozen in the laboratory to kill all macrofauna, washed in fresh water, and oven-dried at $70^{\circ} \mathrm{C}$. Four rows of 3 stainless steel trays (each tray 39 $\mathrm{cm}$ long $\times 23 \mathrm{~cm}$ wide $\times 6 \mathrm{~cm}$ deep) were emplaced flush with the sediment surface in a $6 \times 3 \mathrm{~m}$ grid on Debidue Flat, each row normal to the direction of ebb currents. Trays were filled with azoic sand including a $6 \mathrm{~cm}$ deep column of dyed sand in one tray of each row, and wetted with sea water. A row of 3 trays was collected on Days 1, 3,8, and 23, the height of the sediment tracer recorded, and an equal volume of adjacent sand simultaneously collected from the flat as a control. Although the large quantity of sand necessitated the use of a $1.0 \mathrm{~mm}$ sieve, even juvenile crustaceans were retained. Crustaceans were preserved in rose bengal formalin, identified, measured, and placed in $40 \%$ isopropanol. As in similar studies (e.g. Grassle and Grassle, 1974), immigrants were easily distinguishable from the fragmented animals originally frozen and dried with the sand.

\section{RESULTS}

\section{Sediment Movement}

Sediment on Debidue Flat is a well-sorted mediumfine sand with median particle diameter $(2.35 \varnothing)$, organic content $(0.44 \%)$, and water content $(21 \%)$ similar in both ripple crest and trough (Grant, 1981). The slip faces of ripple crests are ebb-oriented at low tide due to ebb-dominated tidal flow. Ripple spacing and height at the location of faunal cores along the lower intertidal transect $(17.8 \mathrm{~cm}$ wavelength, $3.8 \mathrm{~cm}$ 
Table 1. Hydrography and depth of tidal disturbance throughout the intertidal zone on Debidue Flat. Depth of disturbance determined from dyed sand columns left in situ for single tidal days, March 1978. See text for details

\begin{tabular}{|c|c|c|c|c|c|}
\hline \multicolumn{2}{|c|}{ Intertidal location (m) } & $\begin{array}{l}\text { Mean near bottom } \\
\text { ebb current velocity } \\
\left.\text { (cm s } \mathrm{s}^{-1}\right) \pm \mathrm{SD} \\
\text { (N measurements) }\end{array}$ & \multirow{2}{*}{$\begin{array}{c}\begin{array}{c}\text { Mean depth of } \\
\text { disturbance }(\mathrm{cm}) \\
\pm S D\end{array} \\
\mathrm{~N}=4 \text { replicates } \\
2.17 \pm 1.13\end{array}$} & \multirow{2}{*}{$\begin{array}{c}\text { Maximum value } \\
\text { of disturbance } \\
(\mathrm{cm})\end{array}$} & \multirow{2}{*}{$\begin{array}{l}\text { Water depth }(\mathrm{cm}) \\
\text { at high tide }\end{array}$} \\
\hline High intertidal & $(+0.6)$ & $16.7 \pm 15.6$ & & & \\
\hline Mid intertidal & $(+0.4)$ & $27.8 \pm 14.6$ & $2.85 \pm 0.24$ & 3.00 & 90 \\
\hline Low intertidal & $(+0.2)$ & $32.5 \pm 15.6$ & $1.59 \pm 1.09$ & 2.50 & 125 \\
\hline
\end{tabular}

amplitude) were similar to that within the small sampling area $(17.5,4.5)$. Flume observations indicated that ripple dimensions increased with velocity. This was in agreement with field observations that ripples in the higher intertidal were generally of smaller amplitude $(\sim 1 \mathrm{~cm})$ as expected from decreased bottom current velocity there (Table 1). Depth of sediment disturbance however, did not follow the decrease in current velocity and bedform size from low to high intertidal areas (Table 1). There was no significant difference between depth of disturbance at the three intertidal levels (Jonckheere's test, $p>0.05$, Hollander and Wolfe, 1973). Because water depth in addition to current velocity is an important component of sediment transport, the Froude number (F), a dimensionless index of flow regime which incorporates the variable intertidal water depth (see Menard, 1950), was calculated for field and laboratory data:

$$
F=V\left[(g y)^{1 / 2}\right]^{-1}
$$

where $V=$ water velocity (cm s$~^{-1}$ ); $g=$ gravitational acceleration $\left(980 \mathrm{~cm} \mathrm{~s}^{-2}\right) ; y=$ water depth $(\mathrm{cm})$. The critical erosion velocity (Postma, 1967) at which grains of a given size begin movement as ripples was determined in the flume to be $21 \mathrm{~cm} \mathrm{~s}^{-1}$ for Debidue Flat sand, corresponding to a flume value of $F=0.198$ on a smooth bed. According to Menard's (1950) flume studies, critical erosion velocity is reduced on a previously rippled bed by $27 \%$ for grain size comparable to Debidue Flat. Once in motion, grains remain so at twothirds their critical erosion velocity (Menard, 1950; Postma, 1967). Incorporating the above adjustments and extrapolating to the field, sediment on the rippled surface of the sample site would be transported at about $F=0.198(0.73)=0.144$ and remain in motion until $F=0.144(0.67)=0.096$. Froude numbers throughout an ebb tidal flow are given for 3 intertidal levels in Fig. 1. Although ripple migration and disturbance of the bed proceeded for a greater portion of ebb flow in lower intertidal areas, they occurred at all levels, even where mean ebb current velocity was subcritical (Fig. 1, Table 1). Initiation of bedform movement by a sudden increase in current velocity (and thus Froude number) has also been observed on other intertidal sandflats (Klein and Whaley, 1972). The rate of ripple migration in the flume was measured over a small range of current velocity (mean $=31.42 \pm$ $1.54 \mathrm{SD} \mathrm{cm} \mathrm{s}{ }^{-1}$ ) to be $9.71 \times 10^{-3} \pm 4.25 \times 10^{-3} \mathrm{SD}$ $\mathrm{cm} \mathrm{s}^{-1}$. Bedforms produced at these flume velocities were similar in size to those in the lower intertidal zone at comparable current velocity, and provide a rough estimate of horizontal ripple movement in lower intertidal areas.

\section{Faunal Distribution}

The crustacean fauna (exclusively Peracarida) from bedform samples consisted mostly of the haustoriid amphipods Acanthohaustorius millsi Bousfield $(44.8 \%$

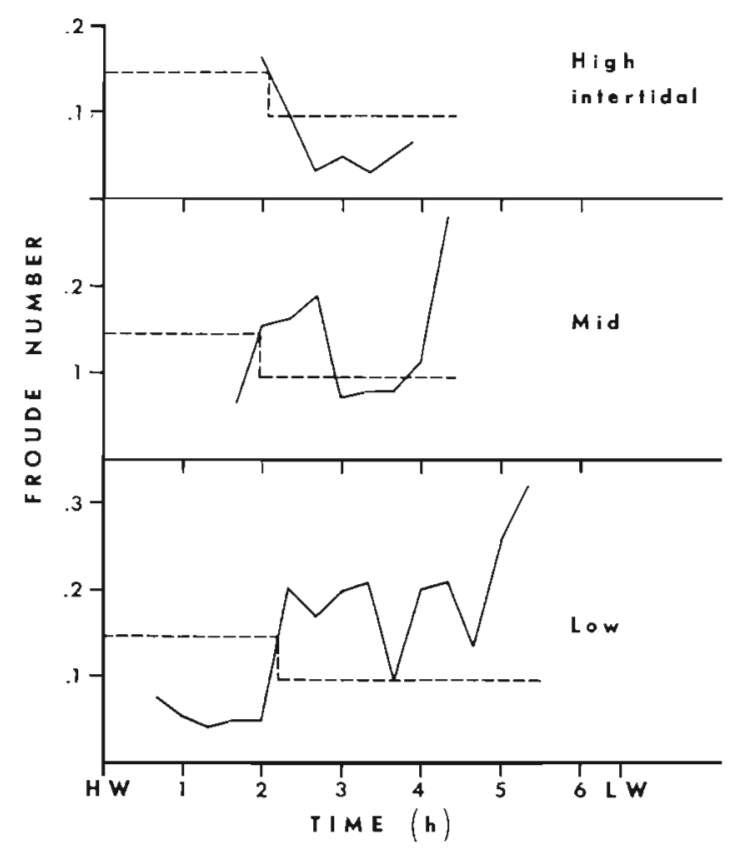

Fig. 1. Froude number versus time from high tide at 3 intertidal locations on Debidue Flat. Dotted line: critical flumedetermined Froude number at which sediment transport is initiated $(F=0.144)$, adjusted for flow on a previously rippled bed according to Menard (1950). After sediment is in motion, critical value drops to $F=0.096$ needed to maintain movement (Menard, 1950). The last point of measurement is where water depth was too shallow for the current meter 
of individuals) and Pseudohaustorius caroliniensis Bousfield (43.7\%). Other crustaceans included the amphipod Monoculodes edwardsi Holmes and the isopod Cyathura burbancki Frankenburg. Along the low intertidal transect, there was no significant difference in pairwise comparisons of number of peracarid individuals between crest surface and crest subsurface samples (Wilcoxon signed-rank test, $p>0.05$, Table 2 ).

Table 2. Distribution of crustaceans in sand ripples at 2 sites in the low intertidal zone $(+0.2 \mathrm{~m})$ on Debidue Flat. Ripples were $15-20 \mathrm{~cm}$ in wavelength and $4-5 \mathrm{~cm}$ in amplitude Samples from homogeneous area taken in July 1978; along transect in August 1978. NS-not significant ( $p>0.05)$

\begin{tabular}{|lcc|}
\hline Core location & $\begin{array}{c}\text { Mean \# individuals } \\
\mathrm{cm}^{-2} \pm \mathrm{SD}\end{array}$ \\
& $\begin{array}{c}\text { Homogene- } \\
\text { ous area } \\
\left(2 \mathrm{~m}^{2}\right)\end{array}$ & $\begin{array}{c}\text { Transect } \\
(50 \mathrm{~m})\end{array}$ \\
$\mathrm{N}=5 \mathrm{cores}$ & $\mathrm{N}=6 \mathrm{cores}$ \\
\hline Crest surface $(0-5 \mathrm{~cm}$ depth) & $2.40 \pm 1.82$ & $2.50 \pm 4.68$ \\
Crest subsurface $(5-10)$ & $2.20 \pm 1.30$ & $2.17 \pm 0.83$ \\
Pooled crest $(0-10)$ & $4.60 \pm 0.67$ & $4.67 \pm 6.22$ \\
Trough $(0-10)$ & $2.80 \pm 2.95$ & $0.33 \pm 0.82$ \\
& & $\mathrm{NS}$ \\
$\mathrm{H}_{\mathrm{A}}:$ Crest surtace $\neq$ crest subsurface & $\mathrm{NS}$ & $\mathrm{P}<0.05$ \\
$\mathrm{H}_{\mathrm{A}}$ : Pooled crest $\neq$ trough & $\mathrm{NS}$ & \\
\hline
\end{tabular}

These 2 sections were pooled into a single $10 \mathrm{~cm}$ trough core; there were significantly more crustaceans occurring in crests than in troughs (Wilcoxon signedrank test, $p<0.05$, Table 2). Data from the small sampling area indicated no significant difference between crest surface and crest subsurface pairs (Wilcoxon signed-rank test, $p>0.05$, Table 2). Crustaceans were more abundant in crests in 4 out of 5 crest-trough pairs from the small area but these differences were not significant (Wilcoxon signed-rank test, $p>0.05$, Table 2).

\section{Recolonization Experiments}

A pilot colonization experiment was conducted in June 1978, at the end of the reproductive period of Acanthohaustorius millsi. On a single tidal day, azoic sand was colonized to $\sim 40 \%$ of crustacean density found in a control sample and most of the immigrants were juvenile A. millsi. In the main experiment (July and August), colonization of azoic sand by crustaceans was a significant function of time (Fig. 2, $p<0.05$, $r=0.77$ ). Because the pilot study suggested a more rapid colonization rate, tray collections were concentrated in the initial sampling dates. Although a number of complex models could significantly fit this regres- sion, immigration was adequately described by the linear equation

Peracarid numbers $\left(0.09 \mathrm{~m}^{-2}=1.01\right.$ (Days) +0.87

Control samples from all dates, averaged to characterize background sediment densities, were typically variable due to faunal patchiness (Grant, 1980) and contained $41.50 \pm 11.72 \mathrm{SE}$ peracarids $\left(0.09 \mathrm{~m}^{-2}\right)$. Extrapolation of the regression past Day 23 indicated that azoic trays would probably reach control densities in approximately one month (Fig. 2).

Eight crustacean species occurred in azoic trays including amphipods, isopods, and decapods. The total number of crustacean species on Days 1, 3, 8, and 23 were $2,3,3$, and 5 respectively. Acanthohaustorius millsi and Pseudohaustorius caroliniensis were the most abundant species as in bedform samples. All nonhaustoriid species except the caridean shrimp $O g y$ rides alphaerostris Kingsley (5 individuals on Day 8, 2 on Day 23), were represented by only $1-3$ individuals. 0 . alphaerostris is not truly intertidal (Pearse et al., 1942) and was apparently stranded in standing water that sometimes remained in trays at low tide. The depth of disturbance in trays as indicated by tracer sand was similar to that observed in core experiments. Sand in trays displayed a rippled surface identical to the surrounding sediment.

In order to collect drifting animals, horizontal traps (1 mm mesh, see Williams and Hynes, 1976) were placed on Debidue Flat for 24 h periods. These collected larval fish, mysids, and epibenthic amphipods and decapods, but were not quantitatively useful due to clogging by ctenophores (Grant, unpubl.). The only infaunal crustacean species collected was Acanthohaustorius millsi. These experiments and the

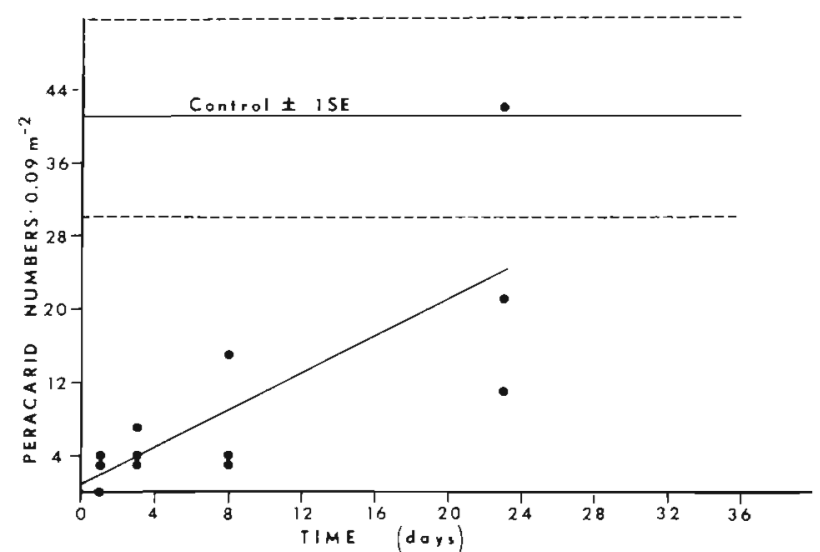

Fig. 2. Colonization curve of peracarid numbers found in azoic sediment trays, July-August 1978. Each point represents a single tray $\left(0.09 \mathrm{~m}^{2}\right)$. Control density $(\longrightarrow)$ determined from the mean of 4 ambient samples shown $\pm 1 \mathrm{SE}$ (---). Dotted line is a portion of the predicted regression past Day 23; curve will then presumably become asymptotic in the vicinity of control densities (see text) 
results of plankton tows in a North Carolina estuary (Williams and Bynum, 1972) as well as in North Inlet (personal observation) confirm the presence of haustoriids in the water column. The above information coupled with the findings of flume studies (Grant, 1980) suggests that most colonization of azoic sand occurred via the water column. Because the tray experiments were designed to investigate benthic-pelagic exchange, the colonization rate obtained applies mostly to the settlement of infauna from the water column. Any inhibition by tray sides and bottom to the entrance of burrowing animals is therefore inconsequential.

\section{DISCUSSION}

Bedform migration and tidal reworking are constant but discontinuous features of the sedimentary environment of Debidue Flat. On a sand body characterized by tidal-velocity asymmetry, ripple migration may proceed during only one phase of the tidal cycle (Klein, 1970). Although ripple size and migration rate are useful as relative measures of current velocity and bed transport, they do not reveal the depth of current reworking at this site. The results of this study and those of Klein (1970) indicate that the depth of disturbance is greater than the depth of bedform troughs. My observations did not include flood tide events or extremely shallow ebb runoff during which time Froude numbers and turbulence increase, and windinduced waves may cause additional scouring (Klein, 1970). Because the tracer experiments recorded sediment transport from both flood and ebb flow, they were more indicative of sand movement relevant to the infauna than ripple measurements.

The population of the dominant macrofaunal species on Debidue Flat, Acanthohaustorius millsi, is concentrated at 2-6 cm sediment depth (Grant, 1981) and is thus partially exposed to tidal disturbance. Sand-burrowing crustaceans are extremely sensitive to changes in hydrostatic pressure (Creutzberg, 1975) and haustoriid amphipods may to some extent avoid disturbance by a rheo- or geotactic response. The fact that amphipods were able to accumulate in colonization trays suggests that some such mechanism occurs. Nevertheless, individuals are washed out of the sand at flume currents which exceed critical erosion velocity (Grant, 1980). Furthermore, haustoriids actively enter the water column in response to diminished sedimentary food levels (Grant, 1980) or excessive crowding (Croker, 1967). Lunar and tidal emergence rhythms are known in the closely related pontoporeiid amphipods (Preece, 1971) and may also occur in the Haustoriidae (Williams and Bynum, 1972).
Distribution of animals in the mobile sand layer may provide further insight into faunal tidal transport, but few observations exist on the spatial relations of benthos in bedforms. Sameoto (1969) found haustoriids to be concentrated in troughs and attributed this distribution to active preference by the animals. An alternative hypothesis is that organisms would be passively deposited in troughs during subcompetent flow as occurs with detritus (Howard and Dorjes, 1972) or less mobile infauna such as bivalves (Pamatmat, 1968). Although dead haustoriids on a plane flume bed were transported by current velocities well below critical threshold of Debidue Flat sediment, a model of peracarid transport as passive grains is insufficient. This conclusion was implied by Spaargaren (1979) for other benthic crustaceans. Superior swimming ability and morphological adaptations afford sand-bottom crustaceans a large degree of control over passive transport (Bousfield, 1970; Eleftheriou and Nicholson, 1975). In any event, there are numerous possible reasons for the greater abundance of peracarids in ripple crests, and one may speculate that both hydrodynamic and ecological factors are involved (Eckman, 1979). Both sand ripples and biogenic structures (i.e. feeding mounds, tube caps, etc.) are important in the small-scale distribution of infauna, but the latter have been emphasized and ripples largely ignored. Bedforms should be further studied as a potential source of spatial heterogeneity in the sediment.

Although the distribution of crustaceans in bedforms apparently does not reflect passively sorted re-entry into the sand, colonization experiments provide information on the rate of settlement of suspended macrofauna. My results suggest that tidal disturbance (and most likely active drift) produces considerable movement of haustoriid populations. As a result of a shallow distribution in the sediment, Acanthohaustorius millsj appeared in azoic trays after one day. Pseudohaustorius caroliniensis is concentrated at $10-20 \mathrm{~cm}$ in the sand (Grant, 1981) and is less susceptible to washout; it only appeared in trays on Day 23. A third haustoriid, Lepidactylus dytiscus Say, occurs in the upper sand layer on Debidue Flat, but is rare in the region where trays were emplaced (Grant, unpubl.). Whether this species never drifted into the azoic sand, or settled and subsequently emigrated, its absence in trays demonstrates that intertidal sand-bottom zonation patterns can be maintained despite movement of animals into the water column (see also Alheit and Naylor, 1976).

The time required for trays to attain the peracarid density observed in ambient sediment is estimated from Fig. 2 to be about one month. However, the rapid influx of juveniles observed in the pilot recolonization experiment emphasizes that colonization rates may be related to peracarid reproductive activity as well as to 
hydrodynamic parameters. It is assumed that the curve in Fig. 2 will become asymptotic to, rather than overshooting, control levels. Haustoriids respond to shortage of food or space by leaving the sediment (Croker, 1967; Grant, 1980), and competitive interactions and/ or tidal disturbance would prevent local overabundance in colonization trays. The dried sand in trays may have initially been unattractive to haustoriids or other amphipods (Meadows, 1964; Grant, 1980), but exposure to natural conditions should have restored microbial activity within a few days (e.g. Hargrave, 1972). This factor may have caused colonization to proceed more slowly in the initial stages. Further experimentation is necessary to determine the exact shape of the colonization curve.

Recognizing these limitations, the observed rate is nonetheless comparable to macroinfaunal colonization seen in similar tray experiments (Grassle and Grassle, 1974; McCall, 1977). In contrast however, recolonization in the latter studies began with opportunistic polychaetes, settling in the enormous densities characteristic of these species. Opportunists soon gave way to equilibrium species (sensu McCall, 1977) as biogenically-and/or physically-induced succession occurred (Rhoads et al., 1978). Recolonization in the highenergy lower intertidal areas of Debidue Flat is markedly different from this sequence. Constant movement and low organic content of the sediment preclude extensive biogenic habitat modification (e.g. surface binding and pelletization) and may inhibit colonization by sedentary species (Beukema, 1976). Colonization occurred from hyperbenthic movement of adults or juveniles (peracarids have no larval stages) as suggested by Santos and Simon (1980). This result is in contrast to other studies in which virtually all immigration was due to pelagic larval stages (Grassle and Grassle, 1974; McCall, 1977).

Some portion of suspended infaunal biomass that would otherwise return to the sediment is undoubtedly removed by predators. Amphipods and other crustaceans are important prey for fishes (Fincham, 1974; Beukema, 1976) and are more subject to predation without the protection of the infaunal habitat (Nelson, 1979). This flow to planktonic predators may be particularly significant when juvenile amphipods are abundant in the water column. The passive and active planktonic excursions of the Haustoriidae, an abundant and diverse family on the US East Coast (Maurer and Aprill, 1979), suggest that high-energy substrata are important in estuarine trophic dynamics. The increasing body of literature on adult infauna in the water column, especially peracarids, must be incorporated into present ideas about the structure of benthic communities and their coupling with the water column.
Acknowledgements. This study is a portion of a Ph. D. dissertation conducted at the University of South Carolina. D. C Rhoads kindly provided dccess and help with the flume. Thanks are extended to B. C. Coull, R. J. Feller, M. A. Palmer, S. E. Stancyk, and F. J. Vernberg for critically reviewing the manuscript, and to J. Spurrier for statistical advice. Support for this work was provided by the Belle W. Baruch Institute and the Southern Regional Education Board. Contribution No. 399 of the Belle W. Baruch Institute for Marine Biology and Coastal Research

\section{LITERATURE CITED}

Alheit, J., Naylor, E. (1976). Behavioural basis of intertidal zonation in Eurydice pulchra Leach. J. exp. mar Biol Ecol. 23: 135-144

Beukema, J. J. (1976). Biomass and species richness of the macrobenthic animals living on the tidal flats of the Dutch Wadden Sea. Neth. J. Sea Res. 10: 236-261

Bousfield, E. L. (1970). Adaptive radiation in sand-burrowing amphipods. Chesapeake Sci. 11. 143-154

Creutzberg, F. (1975). Orientation in space: amimals: invertebrates. In: Kinne, O. (ed.) Marine ecology, Voi. III, Physiological mechanisms, Part 2. Wiley, Chichester, pp. $555-653$

Croker, R. A. (1967). Niche diversity in five sympatric species of intertidal amphipods (Crustacea: Haustoriidae). Ecol. Monogr. 37: 173-200

Eckman, J. E. (1979). Small-scale patterns and processes in a soft-substratum, intertidal community. J. mar. Res. 37 $437-457$

Eleftheriou, A., Nicholson, M. D. (1975). The effects of exposure on beach fauna. Cah. Biol. Mar. 16: 695-710

Fincham, A. A. (1970). Amphipods in the surf plankton. J. mar. biol. Ass. U.K. 50: 177-198

Fincham, A. A. (1974). Periodic swimming behavior of amphipods in Wellington Harbour N. Z. J. mar. Freshw. Res. 8: 505-521

Grant, J. (1980). A flume study of drift in marine infaunal amphipods. Mar Biol. 56: 79-84

Grant, J. (1981). Factors affecting the occurrence of intertidal amphipods in reducing sediments. J. exp. mar. Biol. Ecol. 49: $203-216$

Grassle, J. F., Grassle, J. P. (1974). Opportunistic life histories and genetic systems in marine benthic polychaetes. J. mar Res. 32: 253-284

Hargrave, B. T (1972). Aerobic decomposition of sediment and detritus as a function of particle surface area and organic content. Limnol. Oceanogr. 17: 583-596

Holland, A. F. Polgar, T T (1976). Seasonal changes in the structure of an intertidal community. Mar Biol. 37: 341-348

Hollander, M., Wolfe, D. A. (1973). Non-parametric statistical methods, Wiley, New York

Howard, J. D., Dorjes, J. (1972). Animal-sediment relationships in two beach-related tidal flats; Sapelo Island, Georgia. J. Sed. Petrol. 42: 608-623

Humphries, S. (1977). Seasonal variation in morphology at North Inlet, South Carolina. Ph. D. Dissertation, University of South Carolina, Columbia

Kjerve, B., Proehl, J. A. (1979). Velocity variability in a crosssection of a well-mixed estuary. J. mar Res 37.409-418

Klein, G. D. (1970). Deposition and dispersal dynamics of intertidal sand bars. J. Sed. Petrol. 40: 1095-1127

Klein, G. D., Whaley, M. L. (1972). Hydraulic parameters controlling bedform migration on an intertidal sand body. Geol. Soc. Am. Bull. 83: 3465-3470 
McCall, P. L. (1977). Community patterns and adaptive strategies of the infaunal benthos of Long Island Sound. J mar. Res. 35: 221-266

Maurer, D., Aprill, G. (1979). Intertidal benthic invertebrates and sediment stability of the mouth of Delaware Bay. Int. Revue ges. Hydrobiol, 64: 379-404

Meadows, P. S. (1964). Experiments on substrate selection by Corophium species: Films and bacteria on sand particles. J. exp. Biol. 41: 499-511

Menard, H. W (1950). Sediment movement in relation to current velocity. J. Sed. Petrol. 20: 148-160

Myers, A. C. (1977). Sediment processing in a marine subtidal sandy bottom community. I. Physical aspects. J. mar. Res. 35: 609-632

Nelson, W. G. (1979). Experimental studies of selective predation on amphipods: Consequences for amphipod distribution and abundance. J. exp. mar. Biol. Ecol. 38: 225-246

Pamatmat, M. M. (1968). Ecology and metabolism of a benthic community on an intertidal sandflat. Int. Revue ges. Hydrobiol. 53: 211-298

Pearse, A. S., Humm, H. J., Wharton, G. W. (1942). Ecology of sand beaches at Beaufort, North Carolina. Ecol. Monogr. 12: $135-190$

Postma, H. (1967). Sediment transport and sedimentation in the estuarine environment. In: Lauff, G. H. (ed.) Estuaries. Publs Am. Ass. Advmt Sci. 83: 158-180

Preece, G. S. (1971). The swimming rhythm of Bathyporeia pilosa (Crustacea: Amphipoda). J. mar. biol. Ass. U. K. 51: $777-791$

Rhoads, D. C., Aller, R. C., Goldhaber, M. B. (1977). The influence of colonizing benthos on physical properties and chemical diagenesis of the estuarine seafloor. In: Coull,
B. C. (ed.) Ecology of marine benthos. Univ, of South Carolina Press, Columbia, pp. 113-138

Rhoads, D. C., McCall, P. L., Yingst, J. Y. (1978). Disturbance and production on the estuarine seafloor Am. Sci. 66: $577-586$

Sameoto, D. D. (1969). Some aspects of the ecology and life cycle of three species of subtidal sand-burrowing amphipods (Crustacea: Haustoriidae). J. Fish Res. Bd Can. 26: $1321-1345$

Santos, S. L., Simon, J. L. (1980). Marine soft-bottom community establishment following annual defaunation: Larval or adult recruitment? Mar Ecol. Prog. Ser 2: 235-242

Spaargaren, D. H. (1979). Hydrodynamic properties of benthic marine crustacea. I. Specific gravity and drag coefficients. Mar Ecol. Prog. Ser. 1: 351-359

Steele, J. H., Munro, A. L. S., Giese, G. S. (1970). Environmental factors controlling the epipsammic flora on beach \& sublittoral sands. J. mar biol. Ass. U. K. 50: 907-918

Tenore, K. R. (1977). Food chain pathways in benthic communities: A review with new observations on sediment resuspension and detrital recycling. In: Coull, B. C. (ed.) Ecology of marine benthos. Univ. of South Carolina Press, Columbia, pp. 37-53

Williams, A. B., Bynum, K. H. (1972). A ten year study of meroplankton in North Carolina estuaries: Amphipods. Chesapeake Sci. 13: 175-192

Wiliams, D. D., Hynes, H. B. N. (1976). The recolonization mechanisms of stream benthos. Oikos 27 $265-272$

Woodin, S. A. (1978). Refuges, disturbance and community structure: A marine soft-bottom example. Ecology 59: $274-284$ 